\title{
'CTIntegration': A Conceptual Framework Guiding Design and Analysis of Integration of Computing and Computational Thinking Into School Subjects
}

\author{
Shuchi Grover \\ shuchig@cs.stanford.edu \\ Looking Glass Ventures, CA
}

\begin{abstract}
A growing number of researchers and educators are working on integrating computing and computational thinking (CT) into various K-12 subjects. This conceptual paper motivates the need for and presents a comprehensive framework (CTIntegration) to guide educators and researchers aiming to design for integration. The paper elaborates on the interconnected elements of domain, computing and CT we well as pedagogy, that must be attended to. It also demonstrates the use of the framework as an analytic tool to examine three case studies of recent CT integration efforts.
\end{abstract}

\section{Introduction}

The integration of computing and computational thinking (CT) into school subjects is gaining appeal and popularity. It has also been an active area of research especially in STEM classrooms as it has the potential to help students to engage in authentic STEM practices (NGSS, 2013). Inspired by Papert's use of coding to teach mathematical thinking (Papert, 1980), many have believed that CT can be a powerful vehicle to use the power of computing to engage with deeper ideas in other disciplines. Denning (2017) has argued that CT was born in the sciences and that it is in the sciences that the idea of CT truly came to life. It is widely believed today that students who learn to develop computational solutions and marshal computational tools, resources, and methods will advance their understanding of subject area content, CT skills, and awareness of modern uses of computation across diverse fields (Lee et al., 2020). Another advantage of integration is that it provides an avenue for students to learn about computing in context, which is a useful pedagogy for teaching CS and CT (Cooper \& Cunningham, 2010). This also alleviates the challenge of having to offer stand-alone computing courses. Thus, researchers and educators alike have embarked on efforts to engage students as early as preKindergarten and elementary school as a means to prepare them with skills and practices of computing for future endeavors in all fields.

The need for a framework for integration

Several efforts have attempted to synthesize integrating of CT into STEM subjects with the goal of abstracting learning from various research projects through conference panels and symposia special issues of journals (e.g., (Grover et al., 2020b, 2020c; Lee et al, 2020; Malyn-Smith et al., 2018). These experiences and attempts to synthesize CT/CS integration ideas have highlighted a need in the field for guidance on how to conceptualize integration - where to begin designing for integration; and the considerations and challenges to be taken into account. Based on representative projects and findings in these syntheses efforts, researchers, teachers, and designers, CT is typically operationalized as pattern recognition, abstraction, generalization, algorithms, decomposition. These are drawn from CSTA/ISTE (2011), Grover \& Pea (2013), and others, that put into action Wing (2006)'s ideas. Or they draw on Weintrop et al. (2016)'s taxonomy of CT integration into science and math that is especially useful for STEM and CT integration efforts that involve a focus on computational modeling and data practices. However, these taxonomies and approaches, while helping operationalize CT, do not suggest how to approach integration. The field is still in guidance of how to integrate effectively (Lee et al., 2018).

Mishra \& Koehler (2007), whose TPACK framework for teacher knowledge related to the use and integration of education technology into teaching provided the inspiration for this work, argued that a unified theoretical and conceptual framework allows us to develop and identify themes and constructs that apply across diverse cases and examples of practice. Having a framework goes beyond merely identifying problems with current approaches; "it offers new ways of looking at and perceiving phenomena and offers information on which to base sound, pragmatic decision making" (p. 1019). They assert that until there is such a framework, the field continues to define the isolated pieces of the puzzle in separate contexts and discrete research studies. A shared theoretical vision, in contrast, provides a larger picture that gives everyday classroom efforts direction and meaning. We believe a comprehensive framework also aids research and design in the field. It provides a sensible point for starting conceptualization and design for integration; and not just curricular design, but also 
design of assessments and teacher professional development. It also provides a robust analytical framework for examining and understanding others' work and examples from which one can learn and build on.

To address this gap, this paper articulates a conceptual framework for integration of computing and CT with other disciplinary subjects in schools. The framework aims to help educators of STEM as well as nonSTEM subjects and CS (especially at the K-12 level) understand the what, why, and most importantly, how. It provides structure in conceptualizing integration of CT into various school subjects - how to approach the process of integration, how to select appropriate topics and tools for integration, as well as how to design and organize appropriate pedagogy, assessment, as well as teacher professional development. The paper concludes with an analysis of three rich examples of integration. These examples have helped both, in the conceptualization and articulation of the framework; and also, in examining the key interconnected elements of integration through the analytic lens of the framework. The analysis also helps demonstrate what makes these good examples of integration - why they are successful in the integration, and what lessons others can learn from them.

CTIntegration Framework: The Intersection of Domain, CS/CT, and Pedagogy CTIntegration takes inspiration from the TPACK framework (Mishra \& Koehler, 2007). Unlike TPACK (that is focused on teacher knowledge), CTIntegration aims to guide design and analysis of integrated learning. That said, it does impact teacher knowledge and teacher PD as well. The framework is also distinct in that the key elements in this framework essentially reflect the integration of two disciplines in the classroom- the subject domain and computing - each with its own set of content, practices and pedagogies. The subject domain could be any school subject - mathematics, science, social studies, language arts, art, music and physical education.

The starting point for conceptualizing a framework for integration computing and CT, and the host discipline (or domain or subject). This integration of two domains was the focus of a 2-part NSF-funded workshop series that examined $\boldsymbol{C T}$ in the disciplines. The workshop convened about 50 teachers and researchers to examine descriptions of integration activities (drawn mostly from STEM classrooms). Five "integration elements" emerged from the workshop (Malyn-Smith et al., 2018) - (a) Understanding complex systems; (b) Innovating with computational representations; (c) Designing solutions that leverage computational power and resources; (d) Engaging in collective sense-making around data; and (e) Understanding potential consequences of actions.

These "CT elements in integration settings" are essentially describing what CT is contributing to the learning activities in an integrated context, i.e., the why of CT integration. However, this analysis of CT from a domain perspective does not go far enough in conceptualizing the nitty gritty aspects of integration. In order to understand the techniques and teaching approaches help accomplish the integration, a crucial third element, pedagogy is needed to address the how of integration. Adding pedagogy to intersect with both domain and computing dramatically transforms the way we can conceptualize integration of CT, and more importantly, that integration magic that happens at the center where all 3 circles intersect (Figure 1a). With these three elements, we not only address domain knowledge, CT, and their intersection, but pedagogy as well, along with the crucial new intersection spaces that involve pedagogy. The framework calls for attention to 3 crucial intersections:
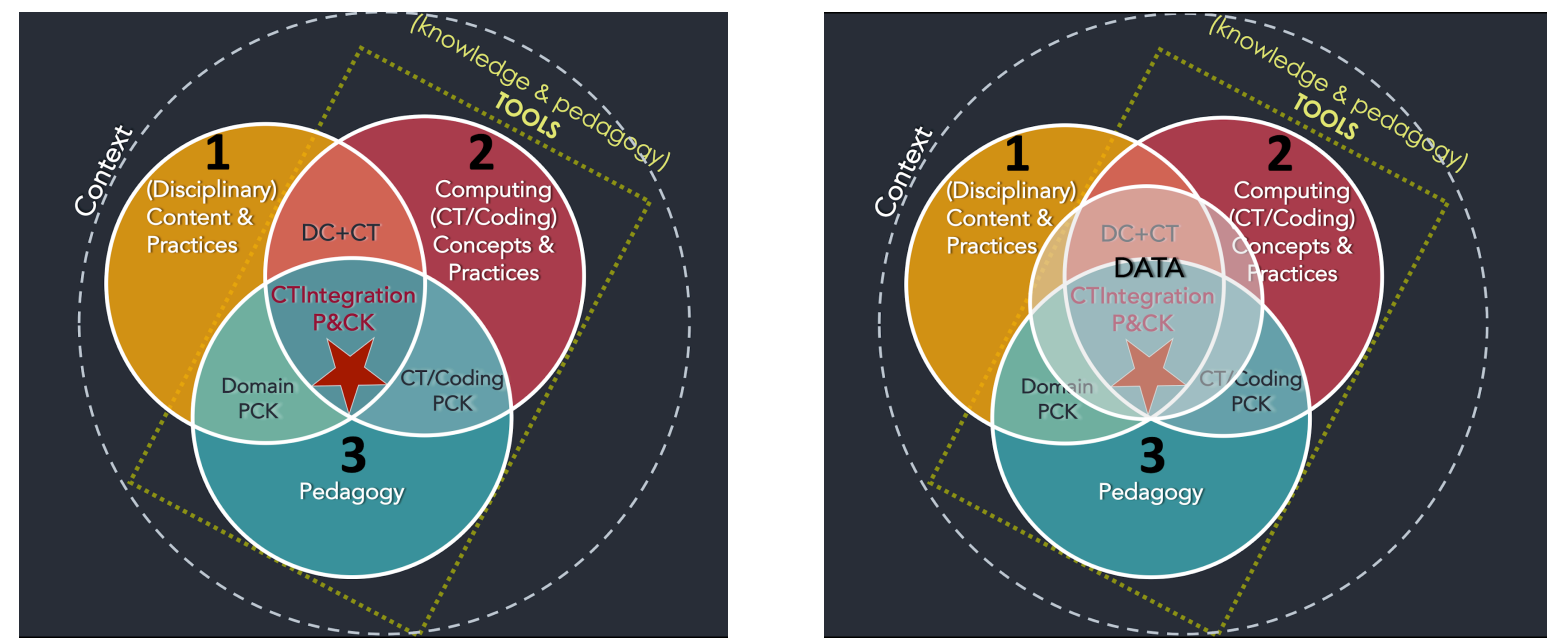

Figure 1(a). The CTIntegration Framework 1(b). Data-centric CT Integration.

- Domain + Pedagogy (Domain PCK): The intersection of domain content and pedagogy is of paramount importance when designing for instruction in any domain (with or without computing). Shulman (1987) 
argued that PCK "is of special interest because it identifies the distinctive bodies of knowledge for teaching. It represents the blending of content and pedagogy into an understanding of how particular topics, problems, or issues are organized, represented, and adapted to the diverse interests and abilities of learners, and presented for instruction" (p.8). It is the understanding of disciplinary content and how to teach it.

- CT/Coding + Pedagogy (CS/CT PCK): This intersection recognizes the vast body of CS education research in K-16 settings to design for an appropriate pedagogy of programming and teaching coding - including unplugged approaches (e.g., Huang \& Looi, 2020) and student misconceptions (e.g., Qian et al., 2020).

- Disciplinary Content $+\boldsymbol{C T}(\boldsymbol{D C}+\boldsymbol{C T})$ : This intersection encompasses ideas related to both, what CT brings to disciplinary learning, and how to select the domain topics in which to integrate computing (see below).

These three intersections contribute, interconnectedly, to the what, why, and how of designing for that integrated learning that happens at the center of the three intersecting components. Such a framework also requires consideration of the ever-present computational environments and tools for coding and automation (since that is one of the key reasons for integration). Computational tools embody their own pedagogy and influence both curriculum and pedagogy in the integration (Frana \& Misa, 2010). The learning philosophy embedded in tools makes them more or less suitable for various purposes - they may be designed for novices, for example, or for specific domains (like R or MATLAB). And finally, as with any conceptual framework for learning designs, there is a context to keep in mind - the context in which teaching \& learning happens, knowledge not only of the domain and of computing, but also of curriculum standards, of students, their prior knowledge, backgrounds, and of cultural context and equitable approaches. These elements together describe CTIntegration - a generative and comprehensive framework for conceptualizing CT/CS integration in various subjects, using a variety of pedagogies, tools, and approaches. Through drawing attention to the relationships among the key components that comprise the integration of CT/CS into a subject, this theoretical framework can catalyze the conceptualization and the practice of CT integration, curriculum \& assessment design, as well as teacher preparation.

In several contexts, data is the linchpin for integration, and increasingly so. For those data-centered approaches to integration, a special case of the framework could be visualized as in Figure 2(b), that highlights data front and center. Data drawn from the domain and relevant to the questions and topics at hand can be a crucial vehicle for integration. However, the tools and practices to problem solve with data are usually computational and drawn on CT practices and pedagogies. Some examples of these are described in Section 3. Ideas of and practices of data science - data sources, data analysis, data transformation, and data representations - become key pieces of the CT integration in these contexts. Examples of data-driven CT integration abound, such as Bootstrap BS:DS (Krishnamurthi et al., 2020), integration of physical computing into social science (Cannell et al., 2020), and integration of CT into environmental systems science in middle school (Covitt et al., 2020).

Discipline-based education research in various disciplines provides ideas for Domain PCK. For example, how modeling and simulations may benefit science education, or what students struggle when they move from arithmetic to algebra, or what approaches help students build mathematical habits of mind in the middle school years, or how students can engage critically in historical social issues to help them understand social inequities in present-day societies. Hence, we next examine more closely the other two intersections, that involve CT.

\section{CS/CT and Disciplinary Content (DC+CT)}

Although this is an intersection we have discussed briefly above, examining it with a view to only understanding what CT looks like from within a discipline (as described in Malyn-Smith et al., 2018) is insufficient. While that framing provides some guidance on integration, educators and designers also need a sense for what makes for good CT integration in the domain. In essence, this intersection must examine not merely as $C T$ in the discipline but $C T$ and the discipline. Not all domain topics benefit equally from integration. $\mathrm{DC}+\mathrm{CT}$ integration dimensions in a framework must seek to answer what topics to content and practices to select for integration. For guidance on the what and where of integration of CT and the discipline, we need to-

- Exploit synergies in topics in the two disciplines - it is important to identify overlaps of domain ideas with CT concepts \& practices. For example, pattern recognition and generalization in mathematics tiling problems are conceptually synergistic with CT, or rules of grammar in a language can be articulated algorithmically or testing and debugging (of models) are synergistic with experimentation and evidencebased practices in science. Crosswalks of standards and frameworks can be useful for finding productive points of integration.

- Identify topics that could benefit from creation of computational artifacts \& leveraging computational power, for example, understanding probabilistic distributions can be easily and powerfully demonstrated and internalized by writing a few lines of code to perform thousands of coin flips or roll of 
the die - an experiment that cannot be done manually. Furthermore, creative computational production has been shown to be an equitable approach that spurs participation of non-dominant communities (Pinkard et al., 2020)

- Examine questions that can be probed and answered with CT/data \& data analysis. Many social studies topics especially benefit from a critical examination of data, and especially quantitative data, from authentic, first-hand sources. Similarly, earth science topics can leverage computational analyses of weather patterns and climate-related dat. Critical, evidence-based thinking and examination of social issues or climate change can be rich and mutually beneficial to developing data science, CT and domain-related understandings.

- Leverage affordances of computational tools and environments that are synergistic with domain ideas, for example, functional programming environments \& Algebra; geometry and languages based on turtle geometry (Abelson \& diSesssa, 1986) e.g., Logo, Scratch, Snap!; sensors and probes for data collection $\&$ analysis in science, geography, and social studies.

- Work with domain teachers to identify productive points of integration. Recent research studies involving development of curricula for integrating computing and domain learning have shown the value of involving and working with teachers. Curricular co-design helps teachers understand CT better and bring their domain expertise to the table. This also helps with curricular uptake and implementation.

\section{CT/Coding and Pedagogy (CS/CT PCK)}

In terms of CT/CS pedagogy and PCK, we have a growing body of empirical evidence-based understanding of how to teach coding and CT. We have a growing sense for unplugged and plugged approaches and when to use which, novice learner misconceptions \& difficulties in K-12 computing education, ideas of what scaffolds to use when and how, how best to introduce different CS, coding, and CT concepts at different grade levels, as well as culturally responsive approaches to engaging diverse learners (Scott, Sheridan, and Clark, 2015). Pedagogical approaches such as PRIMM, Use-Modify-Create, TIPP\&SEE, worked examples and subgoals, live coding, ideas for code tracing, coding for personal meaning, computational action, culturally relevant pedagogy, and tangible computing have been described in a recent handbook on teaching programming (Grover, 2020a). We also have a sense for what an integration progression looks like (Grover, 2018). There is also some understanding of trajectories for CT for different levels of CT integration (e.g., Rich et al., 2017).

\section{Considerations for the Intersection at the Center ( $\mathrm{DC}+\mathrm{CT}+\mathrm{Pedagogy})$}

There are considerations and ways to think about the integration of all three key components of the framework - or the "stuff" that pertains to the center rather than the bi-component intersections. These can also be viewed as broad takeaways for CT integration that concern the intersection of all these components in CTIntegration1. The more tightly the bi-component intersections are designed for, the more meaningful the entire integration. This idea is related to exploiting synergies and symbioses when planning for integration. Choosing the right pedagogies and tools, and right topics, and adopting approaches that leverage as well as benefit both disciplines are necessary to make the magic happen at the center of the 3 intersecting elements.

It is also important to recognize that in some integration efforts, some intersections may be stronger than others, and different contexts may emphasize different aspects of CT. Since domain learning is foregrounded in integration contexts, only those aspects of CT or coding relevant to the context topic are naturally emphasized. For example, not all contexts involve computational model building or data practices

2. Computational tools as well as CT concepts and practices that are tightly intertwined with domain PCK can more seamlessly support integration and learning in the domain without integration feeling like a force fit, and something additional for a subject teacher to take on. When there is a natural alignment between the domain pedagogies and the design and pedagogies inherent or designed for in the computational environment, then the effort required for integration is borne not just by the teacher but shared with the tools and curriculum. This makes the task of integration easier, more enjoyable and beneficial. Examples of this include:

a. The use of functional programming for learning algebraic relationships in the manner achieved through the Bootstrap curriculum (Schanzer et al., 2018).

b. Turtle geometry tools such as Logo, Scratch, and Snap!, to support geometry \& spatial thinking.

c. Modeling \& simulation environments such as Netlogo and C2STEM (Hutchins et al., 2020) that provide support for parameter setup and parameter sweeping, customizing the time tick (delta-t) for the simulation, updating variables with time, visualization (of change in variables over time) 
through data plots, and learning of science topics (such as kinematics) that are based on change over time.

3. The affordances of general-purpose languages versus those of domain-specific languages (e.g. R for Statistics) \& domain-specific abstractions (e.g. the "physics blocks" created for computational modeling in the Snap! programming environment (Hutchins et al., 2020a) may be beneficial in different contexts.

4. Attending to cognitive load, especially if kids don't already know coding, is often a key consideration for integration. Learning to code while also coding to learn can impose cognitive demands that can hamper learning in the domain (Grover, 2018). The issue of cognitive load is very real in integration settings; aforementioned considerations (\#2\&3) can help reduce the cognitive demands of integrated learning.

5. Explicit bridging to original subject learning targets is necessary if the integration is being accomplished almost entirely in a coding environment. Benton et al. (2016) assert of their ScratchMaths curriculum, "The links with the primary mathematics curriculum as a powerful idea should be made explicit" (p. 123). For example, at the end of a $360^{\circ}$ polygon drawing activity in Scratch, teachers link it with their mathematics lessons and could also make links with the concept of multiples which they had also previously covered.

6. Connected to the idea of bridging the coding and domain contexts is the idea of transfer and preparation for future learning (Bransford \& Schwartz, 1999). We want out learners to not only transfer learning to other topics within the domain but also transfer their CT and problem-solving skills that they have learned in the context of the integration curriculum to other problem-solving contexts. (Hutchins et al., 2020a)

\section{Considerations Keeping the Broader Context in Mind}

There are considerations and ways to think about the integration more broadly, for issues that are broader than the specific integrations described.

1. The importance of framing domain integration with computing is important. Framing is a learner's sense of what kind of activity they are engaged in. It's the answer to the questions "What are we doing here? Why are we doing this?" Framing is also tied to pedagogy and how the broader ideas of computing in a subject classroom are conveyed to students. Recent studies have attended to these aspects of integration pedagogy including, helping students to perceive computational models as dialogic peers (Pierson et al. 2020), examining whether students feel like they are "doing coding" or "doing physics" in a science classroom where students build computational models to understand kinematics phenomena (Conlin et al., 2020), and framing coding as designing for authentic use (Sengupta et al., 2020).

2. Design for integrating computing and STEM should leverage affordances of computing to support equity and STEM identity by valuing and connecting to students' cultures (Bell \& Bang, 2015). Production of computational artifacts can afford opportunities to connect to communities and cultures, thus supporting learners from diverge groups, as seen in Cannell et al. (2020)'s Great Migration Visualization (see case study below) and Fields et al. (2018). Integrating computing into subjects also helps further the equity and inclusion mission of "CS For All" especially for learners in groups marginalized from computing and lacking access to dedicated CS courses.

3. Designs for assessment and measurement of learning in integrated settings must take into considerations the primary goals for integration - better domain learning and/or learning of CT and coding. Subjects teachers often foreground learning of the domain for assessment, viewing the CT/coding integration in service of subject learning. Often assessments include separate measurement of domain learning and $\mathrm{CT} / \mathrm{CS}$ learning in addition to assessments that measure aspects of CT integration (for example, Hutchins et al., 2020b).

4. As mentioned above, design for integration must involve teachers in the process of co-design. This serves teachers as a form of professional development and researchers/designers benefit from domain expertise as well as teachers' knowledge of the domain and classroom teaching. This is especially important since usability of the tools and curriculum are as important for teachers in such integration settings as usefulness (Naimipour, Guzdial, \& Shreiner, 2020).

5. The importance of teacher preparation for implementing CT integration cannot be overemphasized. The CTIntegration framework helps in understanding the various aspects of integration that a subject teacher needs to understand. It also highlights to the teacher what CT integration brings to the table and helps them recognize what kinds of things students will be able to do with integration that they could not have done otherwise. Teacher PD must include not only an appreciation of the domain content and practices, and CT concepts and practices addressed by the integration, but also how pedagogy is envisaged. Essentially, teachers must have a thorough understanding of how the various intersections among the interconnected components of the framework are manifested in the integration curriculum. Having an appreciation of computing PCK also includes helping teachers understand the affordances of computational tools. 
CTIntegration could be used to modularize teacher PD and ensure that the additional dimensions and elements introduced by the addition to CT/CS are addressed in addition to PD focused on CTIntegration as required by the curriculum at hand. Without adequate preparation, teachers cannot be expected to execute on an integrated curriculum. ScratchMaths, for example, believes that at least two days of PD are needed to support understanding of the 'big ideas' underpinning the curriculum and pedagogical approach. It is important to realize that a teacher going from a knowledge base of Domain+PCK to everything else that is encompassed in Figure 1 can be a unrealistic demand of any teacher. With an appreciation of this framework, teachers can also be equipped to design their own integration units and activities, perhaps in collaboration with CS teacher colleague(s).

6. Anecdotal and empirical evidence (e.g. Hutchins et al., 2020a) suggests that CT skills and problem-solving with computational tools develop over time. A student does not develop sophisticated ways of thinking about abstraction or algorithmic thinking or debugging from a single course or unit on coding or CS. The seminal work in the learning sciences on how people learn (Bransford, Brown \& Cocking, 2000) suggests that deep conceptual understanding builds from encountering an idea in multiple contexts. Thus, the more CT and CS learning contexts students encounter in school (in addition to or in lieu of learning coding in a dedicated CS course), the deeper their conceptual understanding of CS and CT. This diverse exposure also helps students appreciate the protean nature of computing, which in turn may help attract students of different genders and backgrounds see a future that involves computing based on their diverse interests. Furthermore, integrated teaching and learning benefits from collaboration among people who bring different areas of expertise. As with any design that involves integration and multi-disciplinary learning, it is beneficial to bring multiple perspectives and expertise to the table. It's beneficial to bring together CS teachers in addition to domain experts and subject teachers. Even at the primary level, where teachers are generalists, it might be beneficial to partner with a CS teacher to examine what tools and affordances of computing can be brought to bear on the teaching of a topic.

\section{Examining Integration Through the Analytic Lens of CTIntegration}

This concluding section offers three case studies analyzing CT integration in different subjects and grades through the CTIntegration lens. Each analysis is drawn from papers that describes their why, what, and how of CT integration, including an examination of Domain PCK. Drawing attention to the intersections helps us understand why these could be considered successful exemplars to guide future efforts. While not exhaustive or detailed, these analyses also provide a demonstration of how CTIntegration can be used as a tool for design and research.

\section{C2STEM: Integrating CT into high school science}

Collaborative, Computational STEM (C2STEM; Hutchins et al., 2020b) is a learning environment that aims to promote authentic STEM learning as outlined in the NGSS (2013). Students develop, refine, and interrogate computational models of real-world phenomena using a domain specific modeling language (DSML) in a block-based programming environment (Snap! and its extension, NetsBlox) to promote synergistic learning of science and CT. C2STEM curricular modules include physics (kinematics) and marine biology (coral reef bleaching and climate change). Table 1 is a brief analysis of C2STEM design through the lens of the key intersections in CTIntegration.

Table 1: CTIntegration analysis of C2STEM's Integration of computational modeling in high school science

\begin{tabular}{|l|l|}
\hline \hline Domain PCK: & $\begin{array}{l}\text { - Building models helps students understand system dynamics (Redish \& Wilson } \\
\text { 1993) } \\
\text { - Studying a phenomenon as a step-by-step discrete time process and a sequence of } \\
\text { events is easier for students to comprehend than continuous dynamics (diSessa 2001) }\end{array}$ \\
\hline DC+CT: & $\begin{array}{l}\text { - "Programming can easily capture causal relations and time development, } \\
\text { features central to physics" (Sherin, DiSessa \& Hammer, 1993) } \\
\text { - Visualizations through animation and plots afforded by simulating } \\
\text { computational models help learners judge the legitimacy of model constructs } \\
\text { (Sherin et al., 1993) }\end{array}$ \\
\hline CT/Coding (\& & $\begin{array}{l}\text { - Block-based programming is simpler for novices, and many high school } \\
\text { Tools) PCK: } \\
\text { students are familiar with general-purpose block-based programming } \\
\text { environments like Scratch and Snap! } \\
\text { - Knowledge of customizability and extensibility of Snap! } \\
\text { - Based on CS education research in novice programming, an awareness of Use- } \\
\text { Modify-Create pedagogy, and appreciation of students' difficulty in (a) }\end{array}$ \\
\hline
\end{tabular}




\begin{tabular}{|l|l|}
\hline & $\begin{array}{l}\text { debugging; (b) looping constructs (c) trouble with constructing loop stopping } \\
\text { and conditional expressions involving variables and Booleans }\end{array}$ \\
\hline CTIntegration & - Created domain-specific modeling blocks built in Snap! \\
Design \& & - Extended Snap! to integrate data table/graphing tools to assist with science \\
Pedagogy: & learning as well as debugging; \\
& $\begin{array}{l}\text { - Instructional/inquiry tasks, modeling building and simulation modules, as well } \\
\text { as embedded formative and summative assessments to support and measure } \\
\text { learning of science and CT concepts in middle and high school } \\
\\
\text { - Curricular scaffolds to highlight separation of Initialization (setting up of initial } \\
\text { variable values) \& Simulation step (a block that is called every delta-t time tick } \\
\text { and must involve updating of variable values); } \\
\text { - Scaffolds to assist with the programming in early stages }\end{array}$ \\
\hline
\end{tabular}

\section{ScratchMaths: Integrating CT into elementary school mathematics}

ScratchMaths (Benton et al., 2016) is a two-year computing and mathematics-based curriculum for 9-11-yearold students. Its aim is to enable learners to engage with and explore key mathematical ideas through learning to program in Scratch. Table 2 presents a brief analysis through the lens of the CTIntegration framework.

Table 2: : CTIntegration analysis of ScratchMaths' integration of Scratch coding in elementary school maths

\begin{tabular}{|c|c|}
\hline Domain PCK: & $\begin{array}{l}\text { - Develop mathematical thinking in students is difficult due to: } \\
\text { - Separation of procedures from concepts } \\
\text { - No ownership of mathematics } \\
\text { - Pedagogies that help students develop mathematical habits of mind: pattern } \\
\text { sniffing, visualizing, experimenting, tinkering, conjecturing }\end{array}$ \\
\hline $\mathrm{DC}+\mathrm{CT}:$ & $\begin{array}{l}\text { Through coding, students can- } \\
\text { - Explore mathematics in different representations \& link them } \\
\text { - Explore geometrical structures \& relationships \& the use of variables: } \\
\text { - Engage in reasoning and problem solving } \\
\text { - Take ownership of mathematics (creation and personal meaning) }\end{array}$ \\
\hline $\begin{array}{l}\text { CT/Coding (\& } \\
\text { Tools) PCK: }\end{array}$ & $\begin{array}{l}\text { - The Scratch programming environments has affordances that make geometric } \\
\text { creation, repeating patterns \& generalizations; and visualization easy; } \\
\text { - There is a need for a structured curriculum that moves in/out of } \\
\text { plugged/unplugged (programming \& non-programming) activities }\end{array}$ \\
\hline $\begin{array}{l}\text { CTIntegration } \\
\text { Design \& } \\
\text { Pedagogy: }\end{array}$ & $\begin{array}{l}\text { - Uses Scratch programming in curricular units: Tiling Patterns, Beetle Geometry, } \\
\text { Interacting Sprites, Building with Numbers, Exploring math relationships, } \\
\text { Coordinates with Geometry. } \\
\text { - The curriculum includes extensive teacher support materials and example scripts, } \\
\text { Scratch starter projects, tutorial videos, slides for every lesson, additional } \\
\text { challenges, vocabulary and reference posters. } \\
\text { - 5Es pedagogy: Explore, Explain, Envisage (where students are encouraged to } \\
\text { predict potential outcomes when using different strategies to realize their goal), } \\
\text { Exchange, and bridgE (Any links with conventional mathematics must be made } \\
\text { explicit during the activities and also for the provision of opportunities to re- } \\
\text { contextualize their learning in an environment outside of Scratch). }\end{array}$ \\
\hline
\end{tabular}

\section{'Great Migration Visualization': Integrating CT into social studies}

Great Migration Visualization (Cannell, et al., 2020) is a data visualization project that centers computing on social justice. Circuit Playground Express boards are programmed to allow students to engage with and create visualizations of the great migration of Blacks from the American south during the Jim Crow era. Table 3 presents a brief analysis. It is worth noting that the Bootstrap Social Studies curriculum (BS:DS) similarly takes a data-centric view of CT integration in elementary, middle and high school social studies (Krishnamurthi et al., 2020).

Table 3: Analyzing integration of physical computing into social studies using CTIntegration lens

\begin{tabular}{|l|l|}
\hline \hline Domain PCK: & $\begin{array}{l}\text { - US history taught in schools is inherently white-centered and erases whole } \\
\text { swaths of people from the telling of history. Topics of enslavement and forced } \\
\text { migrations are understudied in US classrooms. }\end{array}$
\end{tabular}




\begin{tabular}{|c|c|}
\hline & $\begin{array}{l}\text { - Culturally relevant pedagogy is needed for critically examining social justice } \\
\text { issues } \\
\text { - Authentic, first-hand data sources make for good social studies experiences } \\
\text { "Current study findings indicate that explicit instruction in the data visualization } \\
\text { literacy is most effective in supporting student content understanding" (p. 1763) }\end{array}$ \\
\hline $\mathrm{DC}+\mathrm{CT}:$ & $\begin{array}{l}\text { (Centered on the affordances of data and tangible computing.) } \\
\text { - Physical computing affords creation of shared, collaborative artifacts that can } \\
\text { support what are usually difficult conversations in classrooms with children } \\
\text { - Public census data sets are available for visualizing migration from 1916-1970 } \\
\text { Sequential events can be depicted through algorithms }\end{array}$ \\
\hline $\begin{array}{l}\text { CT/Coding (\& } \\
\text { Tools) PCK: }\end{array}$ & $\begin{array}{l}\text { - Knowledge of use of Circuit Playground Express boards in classrooms (building } \\
\text { on the project team's prior experiences with e-textiles); } \\
\text { - Data transformations through spreadsheets into proportions that are useful to } \\
\text { display on Circuit Playground Express boards }\end{array}$ \\
\hline $\begin{array}{l}\text { CTIntegration } \\
\text { Design \& } \\
\text { Pedagogy: }\end{array}$ & $\begin{array}{l}\text { - Circuit Playground Express boards feature ten codable NeoPixels, which } \\
\text { students code to display population changes over time; } \\
\text { - Students work with first-hand data sources; engage in data } \\
\text { analysis/transformations and use visualization tools to explain the population } \\
\text { shifts \& explore the multiple ways in which these shifts impact the demographics } \\
\text { of regions across a nation. }\end{array}$ \\
\hline
\end{tabular}

\section{References}

Abelson, H., \& DiSessa, A. (1986). Turtle geometry: The computer as a medium for exploring mathematics. MIT.

Benton, L., Hoyles, C., Kalas, I., \& Noss, R. (2016, February). Building mathematical knowledge with programming: insights from the ScratchMaths project. Suksapattana Foundation.

Bransford, J. D. \& Schwartz, D. L. (1999). Rethinking transfer: A simple proposal with multiple implications. In A. Iran-Nejad and P. D. Pearson (Eds.), Review of Research in Ed, 24, 61-100. Washington, D.C.: AERA

Bransford, J. D., Brown, A. L., \& Cocking, R. R. (2000). How people learn (Vol. 11). Washington, DC: NAP.

Conlin, L., Hutchins, N., Grover, S., \& Biswas, G. (2020). "Doing Physics" And "Doing Code": Students' Framing During Computational Modeling in Physics. In Proceedings of ICLS 2020. ISLS.

Cannell, C., Tofel-Grehl, C., \& Searle, K. (2020). Using Circuit Playground Express and Maps To Visualize Population Migration Data. In Proceedings of ICLS 2020.

Cooper, S., \& Cunningham, S. (2010). Teaching computer science in context. Acm Inroads, 1(1), 5-8.

Covitt, B. A., Berkowitz, A., Boone, R., Caplan, B., Cooper, J., Gunckel, K., ... \& Moore, J. (2020). Developing and Validating a Learning Progression for Computational Thinking in Earth and Environmental Systems Sciences. In Proceedings of the NARST 2020 Annual International Conference. Portland, OR.

CSTA \& ISTE (2011). Operational Definition of Computational Thinking for K-12 Education. Retrieved from https://id.iste.org/docs/ct-documents/computational-thinking-operational-definition-flyer.pdf

Denning, P. J. (2017). Computational thinking in science. American Scientist, 105(1), 13-17.

DiSessa, A. A. (2001). Changing minds: Computers, learning, and literacy. MIT Press.

Fields, D. A., Kafai, Y., Nakajima, T., Goode, J., \& Margolis, J. (2018). Putting making into high school computer science classrooms: Promoting equity in teaching and learning with electronic textiles in exploring computer science. Equity \& Excellence in Education, 51(1), 21-35.

Frana, P., \& Misa, T. (2010). An interview with Edsger W. Dijkstra. Communications of the ACM, 53(8), 4147.

Grover, S. (2018). Computational Modeling: How Can We Manage Cognitive Load When Students Must Simultaneously Learn to Code and Code to Learn in a STEM Classroom? http://shuchigrover.com.

Grover, S. (2020a). Computer Science in K-12: An A-to-Z Handbook on Teaching Programming. Edfinity.

Grover, S. et al. (2020b). Integrating STEM \& Computing in PK-12: Operationalizing Computational Thinking for STEM Learning \& Assessment. In Proceedings of the 14th ICLS, Nashville, TN. ISLS.

Grover, S., Fisler, K., Lee, I., \& Yadav, A. (2020c). Integrating Computing and Computational Thinking into K-12 STEM Learning. In Proceedings of the 51st ACM SIGCSE (pp. 481-482).

Huang, W., \& Looi, C. K. (2020). A critical review of literature on "unplugged" pedagogies in K-12 computer science and computational thinking education. Computer Science Education, 1-29.

Hutchins, N. M., Biswas, G., Maróti, M., Lédeczi, Á., Grover, S.,... \& McElhaney, K. (2020a). C2STEM: A System for Synergistic Learning of Physics and Computational Thinking. JOST, 29(1), 83-100. 
Hutchins, N., Biswas, G., Wolf, R., Chin, D., Grover, S., \& Blair, K. (2020b). Computational Thinking in Support of Learning and Transfer. In Proceedings of ICLS, 2020.

Krishnamurthi, S., Schanzer, E., Politz, J. G., Lerner, B. S., Fisler, K., \& Dooman, S. (2020). Data Science as a Route to AI for Middle-and High-School Students. arXiv preprint arXiv:2005.01794.

Lee, I., Grover, S., Martin, F., Pillai, S., \& Malyn-Smith, J. (2020). Computational Thinking from a Disciplinary Perspective: Integrating Computational Thinking in K-12 STEM Education. JOST, 29(1), 1-8.

Malyn-Smith, J., Lee, I. A., Martin, F., Grover, S., Evans, M. A., \& Pillai, S. (2018). Developing a framework for computational thinking from a disciplinary perspective. In Proceedings of 2nd CTE Conference (p. 5).

McGowan, V.C., Klein, E., Morrison, D. (2019). Engaging Students in Computational Thinking During Science Investigations. Seattle, WA: Univ. of Washington. Retrieved from http://stemteachingtools.org/brief/56

Mishra, P., \& Koehler, M. J. (2006). Technological pedagogical content knowledge: A framework for teacher knowledge. Teachers college record, 108(6), 1017-1054.

Naimipour, B., Guzdial, M., \& Shreiner, T. (2020, October). Engaging Pre-Service Teachers in Front-End Design: Developing Technology for a Social Studies Classroom. In 2020 IEEE Frontiers in Education Conference (FIE) (pp. 1-9). IEEE.

NGSS Lead States. (2013). Next generation science standards: For states, by states. National Academies Press. Papert, S. A. (1980). Mindstorms: Children, computers, and powerful ideas. Basic books.

Pierson, A. E., Brady, C. E., \& Clark, D. B. (2020). Balancing the environment: Computational models as interactive participants in a STEM classroom. Journal of Science Ed. and Technology, 29(1), 101-119.

Pinkard, N., Martin, C. K. \& Erete, S. (2020). Equitable approaches: opportunities for computational thinking with emphasis on creative production and connections to community. ILE, 28(3), 347-361.

Qian, Y., Hambrusch, S., Yadav, A., Gretter, S., \& Li, Y. (2020). Teachers' Perceptions of Student Misconceptions in Introductory Programming. Journal of Ed. Computing Research, 58(2), 364-397.

Redish, E. F., \& Wilson, J. M. (1993). Student programming in the introductory physics course: MUPPET. American Journal of Physics, 61(3), 222-232.

Rich, K., Strickland, C., Binkowski, T., Moran, C., \& Franklin, D. (2017). K-8 learning trajectories derived from research literature: Sequence, repetition, conditionals. In Proceedings of the 2017 ICER (pp. 182190).

Schanzer, E., Fisler, K., \& Krishnamurthi, S. (2018, February). Assessing Bootstrap: Algebra students on scaffolded and unscaffolded word problems. In Proceedings of the 49th SIGCSE (pp. 8-13). ACM.

Scott, K. A., Sheridan, K. M., \& Clark, K. (2015). Culturally responsive computing: A theory revisited. Learning, Media and Technology, 40(4), 412-436. doi:10.1080/17439884.2014.924966

Sengupta, P., Dickes, A., \& Farris, A. (2018). Toward a phenomenology of computational thinking in STEM education. In Computational thinking in the STEM disciplines (pp. 49-72). Springer, Cham.

Sherin, B., diSessa, A. A., \& Hammer, D. (1993). Dynaturtle revisited: Learning physics through collaborative design of a computer model. Interactive Learning Environments, 3(2), 91-118.

Shulman, L. (1987). Knowledge and teaching: Foundations of the new reform. Harvard Ed. Review, 57(1), 123.

Weintrop, D., Beheshti, E., Horn, M., Orton, K., ..., \& Wilensky, U. (2016). Defining computational thinking for mathematics and science classrooms. Journal of Science Education and Technology, 25(1), 127147.

Yadav, A., Larimore, R., Rich, K., \& Schwarz, C. (2019, March). Integrating computational thinking in elementary classrooms: Introducing a toolkit to support teachers. In SITE Conf. (pp. 347-350). AACE. 